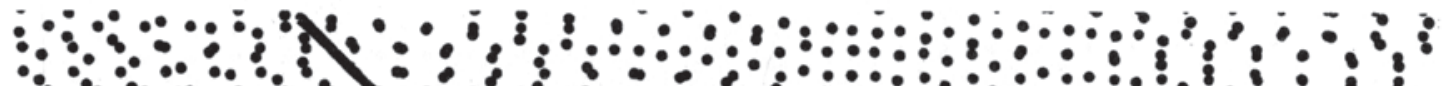
$\therefore$ $: 0^{\circ}$ $\tau^{8}$

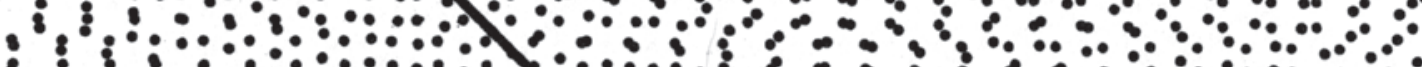
ํ.

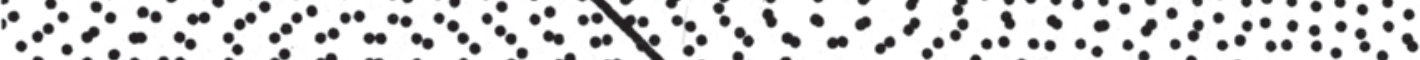
$\therefore$

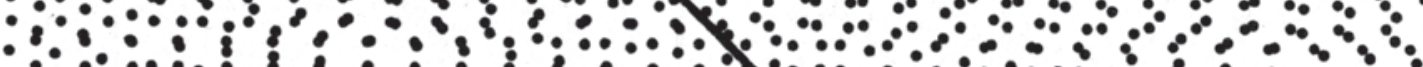

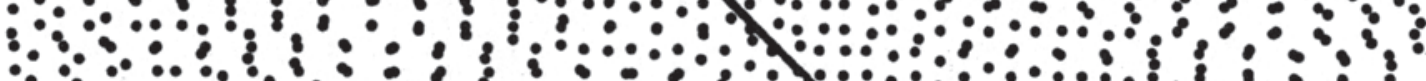
$0^{\circ}$ 0 $8^{8}$ $88^{8}$ 8. ๑ $\therefore$

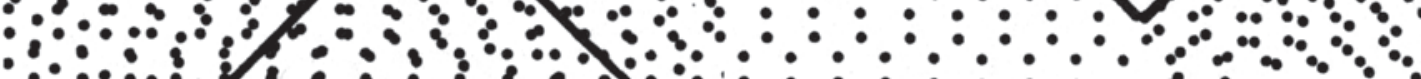

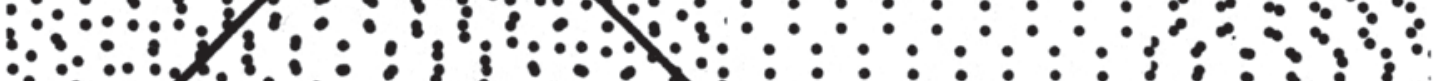

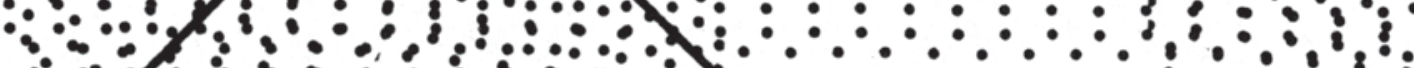
0 : 3

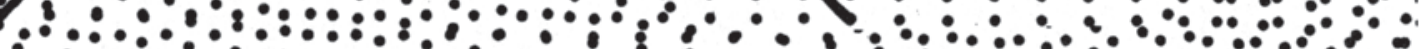
8

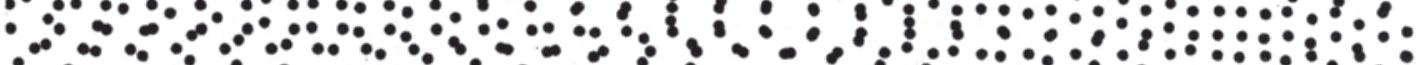
$\because 0$

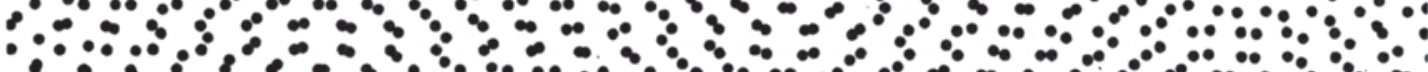

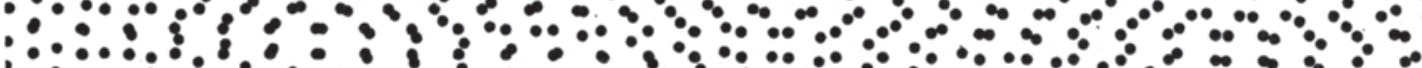
$\because \div: 0^{\circ}$ 
ARS Geraldo Souza Dias*

ano 13

n. 26 Estirâncio: imagem e representação do litoral e a arte contemporânea

\section{Shoreline: Image and Representation of the Seacoast and Contemporary Art}

palavras-chave: estirâncio; pintura de paisagem marítima; litoral paulista.

keywords: shoreline; seascape painting; seashore of the State of

São Paulo.

* professor do Departamento de Artes Visuais da Escola de Comunicações e Artes da Universidade de São Paulo (ECAUSP).
O artigo apresenta uma reflexão sobre a prática sistemática (pesquisa?) desenvolvida na ECA/USP em parceria com o Instituto Oceanográfico da USP nos últimos anos, com foco na representação ou imaginação da paisagem litorânea em Cananéia (litoral sul do Estado de São Paulo), e sugere um levantamento de estudos e/ou práticas artísticas que tenham sido realizados em outras áreas costeiras do Brasil, com o intuito de produzir um futuro mapeamento dessas pesquisas e seus desdobramentos artísticos, didáticos e socioculturais.

The article presents a reflection on the systematic practice (research?) developed at ECA/USP in partnership with the Oceanographic Institute of USP in the last years focused on the representation and imagination of the seascape in Cananéia (South seashore of the State of Sao Paulo) and suggests a survey on the several studies and/or artistic practices developed in other seashore areas of Brazil with the purpose of producing a future mapping of such researches and its artistic, didactic and sociocultural unfolding. 
O mar, fonte inesgotável de pesquisa científica, é também o grande espelho do firmamento, ao refletir sua abóbada luminosa e inspirar diversos artistas ao longo da história da arte. Exerce ainda hoje, na contemporaneidade, forte atrativo na propiciação de experiências únicas e fundamentais, tanto no período de formação artística, quanto no que concerne à apreensão, interpretação e representação de elementos ambientais da cultura litorânea.

A paisagem marítima, em especial a linha demarcatória entre terra e mar, também denominada arcaica e estranhamente de estirâncio, termo associado à instabilidade decorrente do fenômeno das marés, pode ter diversas interpretações, de acordo com a mentalidade vigente em diferentes épocas da história da humanidade. $\mathrm{O}$ historiador francês Alain Corbin ${ }^{1}$ inicia seu $\mathbf{O}$ Território do Vazio com a descrição do mar tenebroso do sec. XV, quando os europeus temiam o mar e os assentamentos humanos geralmente lhes davam as costas, por associarem-no com perigo, morte e podridão. Com o surgimento da medicina higienista no século XVIII, o banho de mar passa a ser mandatário, e, paulatinamente, a Europa vai assistir a uma transformação desse entendimento, que culmina com o início da peregrinação turística, que terá um grande impulso no século XIX, com a valorização das vistas panorâmicas que se abrem para o mar e seu consequente adensamento populacional.

Lembremos que, entre nós, a pintura da paisagem da costa brasileira marca o início das atividades artísticas, com as pinturas Ilha de Itamaracá, de 1637, e Forte dos Reis Magos em Natal, de 1639, ambas de Franz Post, pintor da comitiva de Mauricio de Nassau em Recife, no período que chamamos de "Brasil holandês".

Hoje, crescentes preocupações com o desequilíbrio ecológico, provocado por atividades predatórias, como a pesca industrial, a extração de petróleo, o turismo massivo e o crescimento desordenado das cidades e vilas costeiras, colocam na pauta do debate social a sustentabilidade dos ecossistemas litorâneos.

É nessa perspectiva que, desde 2008, desenvolvo sistematicamente atividades de pintura de paisagem marítima na região de Cananéia, litoral sul do Estado de São Paulo, com alunos de graduação, pós-graduação e bolsistas voltados a projetos comunitários, em parceria com o Instituto Oceanográfico da USP.

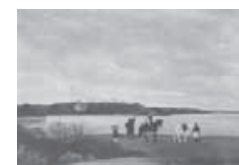

FIGURA 1:

Franz Post. Ilha de Itamaracá, 1637. Óleo sobre madeira, 63,5 x 89,5 cm. Rijksmuseum Amsterdam

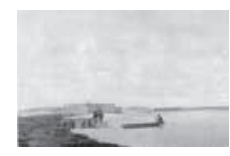

FIGURA 2:

Franz Post. Forte dos Reis Magos, 1639. Óleo sobre madeira, 62 × 95. Museu do Louvre, Paris

1. CORBIN, Alain. 0 território do vazio : a praia e o imaginário ocidental. São Paulo:

Companhia das Letras, 1989. 
Nessa região estagnada economicamente, em virtude de sua transformação em área de preservação permanente, a proposta de criação de um núcleo de pintura vem trazer novas perspectivas à população local, e o contato esporádico com pesquisadores cientistas aponta para a atualização dessa relação, presente nas expedições cientificas dos séculos XVIII e XIX.

\section{0 litoral paulista}

O litoral paulista, com sua costa recortada e suas inúmeras ilhas, praias e regiões ainda recobertas pela Mata Atlântica, contempla um ambiente natural diferenciado no contexto geográfico nacional: congrega inúmeras espécies de animais e vegetais e compõe diferentes ecossistemas. Embora existam trabalhos de gestão ambiental desenvolvidos pela Secretaria de Meio Ambiente, bem como projetos de investigação científica ligados às biociências e, principalmente, oceanográficos, esses projetos muitas vezes ficam restritos a suas áreas de conhecimento, sendo pouco conhecidos pelo público em geral. Suas abordagens científicas e técnicas, apesar de necessárias para o desenvolvimento da investigação ambiental, dificultam o acesso do público leigo à compreensão de seus resultados.

A paisagem marítima foi inspiração para diversos pintores: Benedito Calixto, que documentou a Baixada Santista do começo do século XX em cenas históricas de valor cultural e científico, e também seus contemporâneos, Pedro Alexandrino e Oscar Pereira da Silva, inspiraram-se em recortes do litoral nas suas obras. Mas foi José Pancetti que mais se destacou como o pintor de paisagens marinhas do Estado de São Paulo por excelência.

Entre estrangeiros e brasileiros que se dedicaram à paisagem litorânea de São Paulo, poderíamos citar ainda Antonio Rocco, Antonio Ferrigno, José Marques Campão, Paulo do Valle Jr, Paulo Vergueiro Lopes de Leão, José Monteiro França, Bigio Gerardenghi, João Dutra, Adrian van Emelen, Jorge de Mendonça, Clodomiro Amazonas, Túlio Mugnaini, Giuseppe Perissinotto, Felisberto Ranzini, Edgar Oehlmayer, Nicola Petti, Jorge Furtado de Mendonça, Lucília Fraga, Enrico Manzo, Gentil Garcez, Aldo Bonadei, Silvio Pinto, Durval Pereira, Arlindo Castellani, Inocêncio Borghese, Renzo Gori, Bernardino de Souza Pereira, João Sanseverino, Paulo Alves Siqueira, Antonio Carpentieri, Aldo Cardarelli, Clovis Graciano, Renée Lefevre, Ottone Zorlini, Bruno 
Lechowski, Antonio Eugenio Pascotto, Emygdio Emiliano de Souza e, entre os modernos, Anita Malfatti, Mário Zanini e Alfredo Volpi.

Com o firme propósito de revalorizar essa prática artística, alunos da disciplina "Prática de Pintura I", do Departamento de Artes Plásticas da Escola de Comunicações e Artes da Universidade de São Paulo, sob minha orientação, alojam-se na Base de Pesquisa Dr. João de Paiva Carvalho, do Instituto Oceanográfico da USP, em Cananéia (Base Sul), para concentrarem-se no exame atento da paisagem marítima, com o intuito de recriá-la artisticamente, observando também as nuances científicas voltadas à estrutura oceanográfica presente no local.

A beleza do litoral permanece viva também aos olhos dos estudiosos das ciências ambientais, que se preocupam com os processos que ali ocorrem, vinculados à intervenção humana e aos fenômenos naturais de grande escala.

A experiência desse contato interdisciplinar resultou em duas exposições, realizadas em 2010 e em 2011, e, a partir de 2013, numa oficina de pintura para a comunidade do entorno da Base de pesquisa em Cananéia.

O conjunto de trabalhos apresentados na exposição sinalizou uma integração entre as duas unidades da Universidade - o Instituto Oceanográfico e a Escola de Comunicações e Artes - com a possibilidade de trazer o discurso da arte para um contato direto com o pensamento científico, resgatando procedimentos que já foram comuns nas viagens científicas dos séculos XVIII e XIX.

Em 2010, com a colaboração da Profa. Dra. Elisabete Braga, os alunos de artes visuais passam a trabalhar lado a lado com pesquisadores do IO, favorecendo a aproximação entre a arte e a ciência e suas diversas práticas.

Nas diversas pesquisas desenvolvidas nas Unidades da Universidade de São Paulo, constatam-se práticas que se perdem num contexto de alta especialização e fragmentação. O Instituto Oceanográfico, no entanto, em decorrência de seu histórico multidisciplinar, tem procurado uma visão mais holística no enfoque de suas pesquisas. Além de elementos da biologia, da química, da física, da geologia, também os aspectos humanos são levados em consideração, o que pode explicar a acolhida de nossa proposta: uma investigação teórico-prática das possibilidades atuais de apreensão poética da paisagem do litoral paulista através da pintura, sem excluir outras linguagens da arte contemporânea.
Geraldo Souza Dias

Estirâncio: imagem e representação do litoral e a arte contemporânea

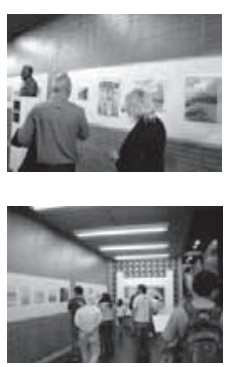

FIGURA 3:

Exposição no átrio do Instituto Oceanográfico da USP, 2010

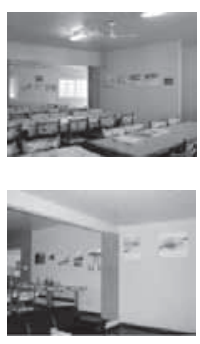

FIGURA 4:

Exposição no salão da Base Sul em Cananéia, 2011 
No desenrolar da pesquisa, o foco passa a ser o estudo da paisagem marítima, fundamentando-se na experiência direta a partir da permanência nas Bases de Pesquisa do Instituto Oceanográfico da Universidade de São Paulo, tanto em Cananéia, no litoral sul do estado de São Paulo, como em Ubatuba, no litoral norte, intensamente utilizadas por alunos, professores pesquisadores nacionais e internacionais e, também, abertas à comunidade do entorno para a prática de atividades de extensão programadas em parcerias.

A diferenciação na formação geográfica desses dois trechos de litoral - um estuário (Cananéia) e uma enseada (Saco da Ribeira, Ubatuba), voltada ao mar aberto, proporciona diversidade ao nível da paisagem em seus elementos, tanto naturais como socioculturais.

A perspectiva apontada, a partir de um embasamento teórico, seria detectar o state of the art da representação paisagística do estirâncio, ao longo da costa brasileira, promovendo a integração das diversas paisagens, tendo como elemento comum a linha de separação entre o liquido e o sólido, o mar e a terra. São produzidas pinturas, principalmente, mas também fotografias e outras expressões artísticas que possam retratar e recriar poeticamente o ambiente marítimo, numa atualização da noção do artista naturalista, que se confunde com o defensor da preservação e do manejo sustentável do ambiente litorâneo, e contribui à sensibilização ecológica das comunidades locais e externas.

As imagens artísticas, por advirem de uma relação sensível e direta com a paisagem natural e a biodiversidade do litoral e de seus cenários científico-culturais, proporcionam uma nova forma de vínculo com a natureza, dando visibilidade a projetos científicos já existentes. Através desses trabalhos, a comunidade frequentadora das bases da USP passa a refletir sobre seu entorno, observa e valoriza o meio ambiente com o qual convive, desenvolve a consciência ecológica, e passa a tratar da sustentabilidade como parte integrante da vida, e não como estudo inacessível.

Conforme assinalamos, o ponto de partida para a retomada dessa

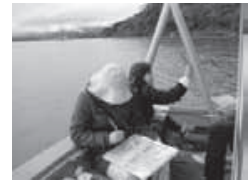

FIGURA 5:

Viagem de estudos pelo estuário do Ribeira de Iguape, 2011 prática é a noção de artista naturalista, comum no século XVIII, quando as fronteiras entre a observação científica e a apreensão do mundo natural através da ilustração artística não eram estanques. Esse período foi marcado pela busca do conhecimento racional, incentivado pelo Iluminismo, e lançou as sementes para o desenvolvimento das ciências naturais modernas. Artistas e biólogos trabalhavam em conjunto, documentando flora e fauna através de procedimentos baseados numa su- 
124

posta racionalidade. Ao mesmo tempo em que pintores naturalistas dispunham de conhecimentos científicos, biólogos eram também capazes de desenhar o que viam, gerando imagens de alta qualidade artística. As ilustrações naturalistas constituem um capítulo importante da história da arte e são frequentes nos trabalhos de pesquisadores como Alexander Von Humboldt, Carl Linnaeus, Karl Friedrich Philip von Martius, Charles Darwin, Ernst Haeckel, entre outros.

No que se refere ao desenvolvimento da linguagem artística, a prática de pintura marinha pode contribuir para a atualização dos procedimentos utilizados pelos artistas naturalistas, sob um enfoque conceitual contemporâneo.

Hoje em dia, nossa relação com a natureza encontra-se esquadrinhada pela ciência e torna-se cada vez mais cultural. A produção da imagem da paisagem contemporânea, além de ser informada pela produção artística histórica, incorpora concepções e modelos advindos da biologia, da arquitetura, da física, da meteorologia e das mais variadas ciências. $\mathrm{O}$ artista contemporâneo tem acesso a essas imagens e sua visão de mundo contamina-se por elas. São imagens fotográficas e midiáticas, gráficos científicos que descrevem o mundo a partir de um ponto de vista muitas vezes diverso daquele da atividade artística tradicional. Assim, a relação atual do artista com a natureza não é mais tão direta, mas está sujeita à interferência de camadas de sentido oriundas da ciência e da comunicação social. Podemos afirmar que ele retoma, em certo modo, os processos de observação artística através do contato direto com a natureza, não de modo ingênuo, mas inserido numa ótica contemporânea.

A natureza, como a vemos agora, não é mais a de um país "intocado" como foi até o século XVIII, mas aquela que se problematiza em nosso dia-a-dia, com a prevista extração de petróleo ou a construção de equipamentos turísticos. A escolha do litoral paulista como corpus inicial para o desenvolvimento da pesquisa reflete essa preocupação.

São discutidos conceitos relativos às questões da artificialidade da paisagem, da visão racionalizada das ciências naturais, da hibridização de processos e metodologias oriundos da ciência e da arte na relação do homem com o mundo natural.

$\mathrm{O}$ contato do homem atual com a natureza ocorre não mais de forma direta e próxima, mas mediado pelo discurso social e científico. Se outrora o homem viveu próximo à natureza, convivendo com seus fenômenos e desenvolvendo uma percepção bastante individualizada destes,
Geraldo Souza Dias

Estirâncio: imagem e representação do litoral e a arte contemporânea

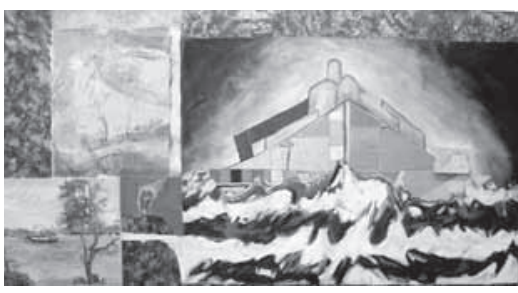

FIGURA 6:

Geraldo Souza Dias, 0 Oceanógrafo, 2010. Óleo e colagem sobre tela, $100 \mathrm{x}$ $200 \mathrm{~cm}$

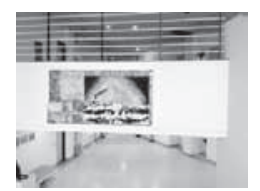

FIGURA 7:

Pintura instalada no novo edifício do IOUSP

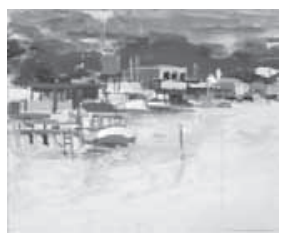

FIGURA 8:

Guilherme Ramos (Café). Base Sul em Cananéia, 2009. Óleo sobre tela, $40 \times 50 \mathrm{~cm}$ 
ARS hoje, com o advento dos meios de comunicação, o acesso à ciência na ano 13 sociedade e a vida em metrópoles, sua relação com o mundo natural senn. 26 sível ganhou níveis de complexidade, que ora exibem conhecimento objetivo e racional, ora tendem a torná-lo distante e inatingível. As percepções históricas da natureza como cenário para a vida social ou seu simbolismo como depositária de conteúdos espirituais e míticos, são hoje acrescidas do discurso da ciência sobre ela. A divulgação científica pelos media tornou nossa percepção da natureza mais ampliada, incorporando conceitos e análises anteriormente acessíveis somente ao público especializado.

Desde o século XVIII, diversos artistas registraram a natureza em suas particularidades objetivas, criando imagens que serviram muitas vezes para estudos científicos de botânica e geografia, por exemplo, ainda que para eles coubesse extrair da natureza sua verdadeira poesia, respeitando-a como manifestação autônoma e propiciadora da atividade criativa.

Embora a pintura tivesse como objetivo documentar o mundo natural, em alguns casos, os artistas não só representavam o que viam, mas até inventavam "realidades" inexistentes, pela empolgação imaginativa com o exotismo de paisagens não familiares. Conforme nos aproximamos do século $\mathrm{XX}$, com o avanço da imprensa, as ilustrações do mundo natural vão se tornando cada vez mais populares, não só entre cientistas, mas também para o público em geral. Com o tempo, a fotografia também passa a ser utilizada para a documentação das espécies, porém o desenho ilustrativo permanece, dada a possibilidade que oferece de isolar e salientar pormenores com clareza e distinção.

A oscilação entre a representação objetiva e a livre interpretação do mundo natural é tema de grande polêmica no mundo artístico, especialmente a partir do século XVIII, em que as mentalidades neoclássicas e românticas convivem lado a lado. $\mathrm{O}$ surgimento da fotografia no século XIX trouxe novos elementos para essa disputa, que se acirra em nossa época, em que se buscam transdisciplinaridades e os limites dos campos do saber atenuam-se.

\section{A paisagem como artificialidade construída}

A pretensão racionalista do pensamento moderno fez com que ao longo do século XX a ciência se tornasse cada vez mais especializada e específica e a arte buscasse um campo autônomo de atuação. A partir da segunda metade do século XX, esse processo se intensifica e a crítica 
ao modernismo busca restabelecer as ligações entre emoção e razão e eliminar os limites dos campos do saber, procurando interações entre as diversas áreas e objetivando um pensamento mais integral.

A ciência, desde o século XIX, caracteriza-se pela tentativa de reunir uma grande quantidade de informação sobre o mundo através do processo da coleta e processamento de dados e elementos, mas esbarra na impossibilidade do acesso a esta informação, por seu volume excessivo e sua linguagem especializada. A obsessiva vontade de explicação do mundo, que remete aos princípios orientadores da ciência, revela-se, portanto, inadequada para a apreensão sensível. Porém, em uma sociedade marcada pela excessiva exposição à imagem, à informação e ao simulacro, essa é quase a única possibilidade de interação entre o homem e o universo que o cerca. Nesse sentido, os artistas apontam para a problemática da desnaturalização do homem, que, por meio dos artefatos da cultura e da ciência, cria para si um mundo artificial e fictício. Podemos aqui recorrer a Maurice Merleau-Ponty ${ }^{2}$ em sua crítica fenomenológica da ciência:

"A ciência manipula as coisas e renuncia a habitá-las. Fabrica para si modelos internos delas e, operando sobre esses índices ou variáveis as transformações permitidas por sua definição, só de longe se defronta com o mundo atual. Ela é, sempre foi, esse pensamento admiravelmente ativo, engenhoso, desenvolto, este parti pris de tratar todo ser como "objeto em geral", isto é, a um tempo como se ele nada fosse para nós, e no entanto, se achasse predestinado aos nossos artifícios".

Em A invenção da paisagem, a pesquisadora francesa Anne Cauquelin $^{3}$ demonstra que, ao invés de ser apenas uma parte da natureza, a paisagem é na verdade seu analogon, isto é, uma construção conceitual humana que busca ser o equivalente da natureza. A autora nos informa que nossa percepção atual de paisagem é influenciada pela forma com que a natureza foi representada pela arte ao longo do tempo, e é através desses modelos cognitivos incutidos em nosso imaginário que podemos percebê-la. Não apenas a imagem da paisagem na pintura, mas a própria natureza do mundo real recebe as conformações que o homem lhe impinge, de modo a apresentar uma aparência mais harmônica ou "natural”. Toda a história do paisagismo comprova essa hipótese, ora buscando uma paisagem mais próxima do que seria o natural idealizado, ora assumindo propositalmente a artificialidade da criação humana.

Também para o historiador britânico Simon Shama ${ }^{4}$, a "paisagem é cultura antes de ser natureza, um constructo da imaginação pro-
Geraldo Souza Dias

Estirâncio: imagem e representação do litoral e a arte contemporânea

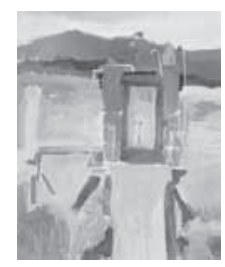

FIGURA 9:

André Ricardo de Almeida. Marégrafo da Base Sul, 2009. Óleo sobre tela, $50 \times 40 \mathrm{~cm}$

2. MERLEAU-PONTY, Maurice. 0 olho e o espírito. São Paulo: Cosac Naify, 2004.

3. CAUQUELIN, Anne. A invenção da paisagem. São Paulo: Martins, 2007. 
ARS jetado sobre mata, água, rocha. No entanto, cabe também reconhecer ano 13 que, quando uma determinada idéia de paisagem, um mito, uma visão, n. 26 se forma num lugar concreto, ela mistura categorias, torna as metáforas mais reais que seus referentes, torna-se de fato parte do cenário”.

É comum que a paisagem que visualizamos não corresponda aos nossos ideais estéticos, porém, nem sempre nos damos conta disso, acreditando que estamos apenas buscando o que seria "o natural". Ao realizarmos uma pintura ou uma tomada fotográfica ou de vídeo, procuramos buscar o melhor ângulo de visão, eliminando do enquadramento o que poderia perturbar a "idéia" de paisagem natural - postes, fios elétricos, automóveis, construções desinteressantes etc.

Os atuais estudos da paisagem têm procurado ampliar essa noção, considerando paisagem não apenas a natureza formatada segundo tradicionais modelos estéticos, mas tudo aquilo que é vivenciado no espaço tridimensional. Um dos principais teóricos a desenvolver estas noções é o americano John Brinckerhoff Jackson ${ }^{5}$, importante teórico dos Cultural Landscape Studies. Na revista Landscape, a partir de 1951, ele propagou um "conceito aberto" de paisagem, numa abordagem que contesta a idéia de modelo ideal, perfeito e estetizante, substituindo-o por uma visão de paisagem enquanto constructo cultural submetido às interações humanas e contaminado por percepções científicas e intervenções tecnológicas. Para ele, "a paisagem não é apenas cenário, tampouco categoria política; ela nada mais é que uma coleção, um sistema de espaços produzidos pelo homem sobre a superfície da terra. Indiferentemente de dimensão ou forma, a paisagem não pode ser entendida apenas como espaço natural. Ela é sempre artificial, sempre sintética, e (...) sujeita a modificações repentinas e imprevisíveis. Nós a criamos e necessitamos dela, porque toda paisagem é um lugar no qual nós, homens, organizamos tempo e espaço”. Essa concepção de paisagem, contrasta com o tradicional conceito de paisagem ideal, e tem influenciado artistas contemporâneos a buscar documentar o mundo da maneira como ele se apresenta, com seus ruídos estéticos e idiossincrasias. A paisagem, conforme percebida na atualidade, passa a ser então um

4. SHAMA, Simon. Paisagem e

Memória. São Paulo: Cia. das Letras, 2009, p. 70.

5. JACKSON, John Brinckerhoff. Discovering the Vernacular Landscape. New Heaven: Yale University Pres, 1984, p. 43. espaço de negociação entre o mundo natural e a construção humana.

"Mas a paisagem sempre guarda em si a melancólica e utópica idéia de retorno, a busca de um ideal sublime e inatingível. A paisagem é ao mesmo tempo uma constatação presente, resultado de acontecimentos passados e o "eco romantizante de uma perspectiva de futuro. Ela representa tanto a promessa do factível como a ameaça da perda da própria paisagem”. 


\section{Conclusão}

A utilização da arte com fins científicos teve um desenvolvimento considerável, sobretudo a partir do século XVIII, quando as ilustrações zoológicas e botânicas se tornaram um importante instrumento para o estudo do mundo natural. Como já observamos, o conceito de paisagem difere da ideia da natureza em si, já que se trata de uma maneira específica de percepção do mundo natural segundo premissas humanas, que podem variar de acordo com as realidades históricas e epistemológicas, e os artistas estão cada vez mais consciente dos desejos e das dificuldades de uma aproximação com o ambiente natural.

A respeito da influência da ciência e do desenvolvimento técnico sobre os artistas modernos, Zygmunt Bauman ${ }^{7}$ comenta:

"Muitos deles receberam sugestões e ânimo (...) da ciência e da tecnologia, os mais desafiadores, aventurosos e irreverentes entre as tropas de assalto do moderno despedaçamento da tradição: impressionistas da ótica antinewtoniana, cubistas da anticartesiana teoria da relatividade, surrealistas da psicanálise, futuristas dos motores de combustão e das linhas de montagem".

Vivenciamos um novo momento, no qual a natureza já não mais comparece como berço original, mas como realidade maleável, virtual, onde se travam disputas éticas e estéticas. Ao invés de um ecologismo vazio e puramente utópico, a arte pode nos oferecer uma visão mais abrangente sobre a questão da natureza, vista não mais como um simples refúgio ou ideal, mas como uma parte do mundo sensível que o homem inexoravelmente altera e com a qual interage, devendo por isso tornar-se mais responsável e consciente.

A interação entre natureza e ciência na arte contemporânea tem se tornado tema de vital importância para o homem atual, que necessita repensar suas relações com o mundo natural a partir de posturas mais conscientes, sensíveis e fundamentadas.

A pesquisa de criação artística permite a verificação de hipóteses levantadas pela pesquisa teórica, e constitui uma contribuição original e poética no campo da relação entre arte e natureza. A escolha do litoral paulista como topos para observação, ao mesmo tempo em que estabelece um recorte necessário, traz a pesquisa poética para perto da comunidade acadêmica, criando um trabalho que parte de uma realidade local para se inserir num contexto mais amplo e universal.
Geraldo Souza Dias

Estirâncio: imagem e representação do litoral e a arte contemporânea

6. FRANZEN, Brigitte; KREBS, Stefanie. Landschaftstheorie. Köln: Verlag der Buchhandlung Walther König, 2005, p. 300.

7. BAUMAN, Zygmunt. 0 mal estar da pós-modernidade. Rio de Janeiro: Jorge Zahar Ed., 1998, p. 24. 
A experiência de artistas, bem como a incorporação de colegas colaboradores, e seus orientandos proporciona o desenvolvimento de um processo criativo coletivo, que estabelece contatos transdisciplinares com pesquisadores das áreas da Oceanografia, Biociências, Ciências Ambientais e outras afins. A sensibilização da comunidade universitária para a necessidade da integração entre as áreas do conhecimento é uma das principais contribuições que se pode oferecer. A arte pode proporcionar conscientização ecológica, sem deixar de buscar perspectivas criativas inovadoras e discussões internas de sua linguagem poética.

\section{Bibliografia complementar}

ACOSTA, Daniel A. Paisagem Portátil: Arquitetura da natureza estandardizada. Tese de Doutorado, São Paulo: ECA/USP, 2005.

CLARK, Kenneth. Paisagem na Arte. Lisboa: Ulisséia, 1961.

DORFLES, Gillo. Naturaleza y Artifício. Lumen, 1972.

HUMPHREYS, Richard. A Paisagem na Arte: 1690-1998 - Artistas Britânicos na Coleção da Tate. São Paulo: Pinacoteca do Estado de São Paulo, 2015. KASTNER, Jeffrey. (org.). Land and environmental art. London : Phaidon Press, 1998.

TARASANTCHI, Ruth Sprung. Pintores Paisagistas. São Paulo: EDUSP/IMESP, 2002.

Pintores do Litoral Paulista. São Paulo:

Sociarte, 2003.

TEIXEIRA LEITE, José Roberto. Dicionário Crítico da Pintura no Brasil. São Paulo: Artlivre, 1988.

TRIMER, Nelsita F. de Campos (org.). Ciência, história e arte: obras raras e especiais do Instituto de Biociências da Universidade de São Paulo. São Paulo: EDUSP : FAPESP, 2009.

VIEIRA, Maria Elena Merge. O jardim e a paisagem: espaço, arte, lugar. São Paulo: Annablume, 2007.

Geraldo Souza Dias, é pintor e professor da Escola de Comunicações e Artes da Universidade de São Paulo. Nascido em São Paulo (1954), graduou-se pela Faculdade de Arquitetura e Urbanismo da USP (1979), com mestrado no Pratt Institute, de Nova York (1984) e doutorado na Universität der Künste Berlin (2000). Em 2005 foi professor visitante do Instituto de Arte Design e Marketing de Lisboa e em 2008, com bolsa da Comissão Fulbright, da University of the Arts, em Filadélfia. Realizou diversas exposições no Brasil e no exterior.

Artigo recebido em 28 de
Agosto de 2015 e aprovado

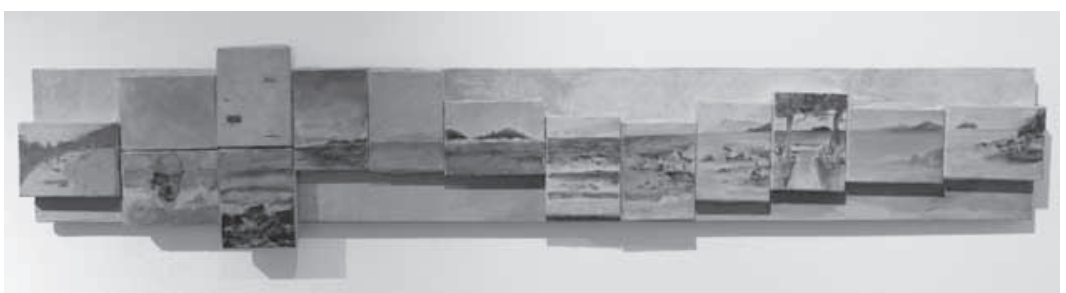

